\title{
IN SITU TEM OBSERVATIONS OF HEAVY ION DAMAGE IN GALLIUM ARSENIDE*
}

\author{
M. W. Bench ${ }^{1}$, I. M. Robertson ${ }^{1}$, and M. A. Kirk ${ }^{2}$ \\ ${ }^{1}$ Dept. of Materials Science' and Engineering, University of Illinois at Urbana \\ Urbana, Illinois 61801 \\ 2 Materials Science Division, Argonne National Laboratory \\ Argonne, Illinols 60439
}

CONF-871124--77

DE88 005984

\section{MASTG}

January 1988

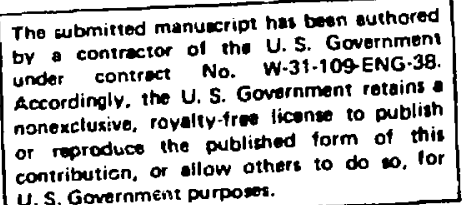

U.S. Government purposes.

\section{DISCLAIMER}

\begin{abstract}
This report was prepared as an account of work sponsored by an agency of the United States Government. Neither the United State: Government nor any agency thereof, nor any of their employees, makes any warranty, express or implied, or assumes any legal liability or responsibility for the accuracy, completeness, or usefu!ness of any information, apparatus, product, or process disclosed, or represents that its use wound not infringe privately owned rights. Reference herein to any specific commariai pindurt, r,rocess, $r$ service by tracie name, trademark, manufacturer, or otherwise does not necessarily constitute or itnply its endorsement, recommendation, or favoring by the United States Government or any agency thercuf. The views and opinions of authors expressed herein do not necessarily state or reflect those of the United States Government or any agency thereof.
\end{abstract}

Submitted to the 1987 Fall Meeting of the Materials Research Society (MRS), November 30 - December 5, 1987, Boston, MA.

* Work supported by the U. S. Department of Energy, BES-Materials Sciences, under Contract W-31-109-Eng-38, and ACO9-76ERO1198 (Univ. of Illinois-Urbana). 
M.W. BeNaH, * I.M. ROEWRISON, * AND M.A. KCRK"*

Dept. of Materials Science and Bngineerirg, University of IIIinois, Urbana, IL 61.801

** Materials Science Division, Arganne National Iaboratory, Argane, Il 60439

\section{ABSTRACT}

Transmission electron microscopy experiments have been performed to investigate the lattice danage crrated by heavy-ion bambardments in GaAs. These experiments have been performed in situ by using the FVEM - Ion Acoelerator Facility at Arganne National Iaboratory. The ion bonbardments (50 keV $\mathrm{Ar}^{+}$and $\mathrm{Kr}^{+}$) and the microsogpy have been carried out at temperatures ranging fram 30 to $300 \mathrm{~K}$. Ion fluenoes ranged fram $2 \times 10^{1.1}$ to $5 \times 10^{13}$ ions $\mathrm{cm}^{-2}$.

Direct-impact amorphization is abserved to ocaur in both $n$-type and semi-insulating GaAs irradiated to $20 \mathrm{w}$ ion coses at $30 \mathrm{~K}$ and roan temperature. The probability of forming a visible defect is higher for low temperature irradiations than for rocm temperature irradiations. The amorphous zones formed at low temperature are stable to temperatures above $250 \mathrm{~K}$. Post implantation arnealing is seen to ocaur at rocm tenperature for all samples irradiated to low doses unil eventually all visible damage disappears.

\section{INIRODUCTION}

The damage produced by ion implantation in GaAs has been the subject of extensive investigation for a nuber of years. Much of this research has focused on the structure of the amorphous layer created at high doses and on the annealing prooesses required to restore the crystalline lattice structure [1]. Also, a considerable amount of work has focused on the structure of the primary damage and the mechanisms by which this damage builds up to form an amorphous layer [2]. Two basic models for the mechanisms by which amorphization occurs in semiconductors have been proposed. In the first, amorphization occurs by a build up of simple damage during irradiation until the defect density is so great that the region spontanecusly collapses to an amorphous state [3]. In the second, small regions are directly amorphized curing indivicual collision cascades and complete amorphization occurs by the accumulation and overlap of these regions [4]. The first model has generally been used to explain the build up of damage for light ians and high temperature, whereas the second has been used to explain the damage created by heavy ions at low temperatures. A more realistic model would be one that allows both mechanisms to ocarr simultaneously and, as a result, a camposite model of anorphous layer production has been developed [5] that includes both and also includes the effects of simultaneous damage annealing. Wile these models provide a good description of the general mechanisms by which the crystalline-to-amorphous transformation ocours, the esact mechanisms remain controversial.

Most investigations made on the build up of damage towand the production of an amorphous layer have been made by the Putherford backscatteringchanneling technique $[6,7,8]$. Although much information has been gathered using this technique, it has the limitation that no direct assessment of the actual damage structure can be made. The direct observation of ion implantation incuced damage structure is well suited to TEM investigations. 
Fawver, as will be shown, the cocurrence of rooin temperatame annaling in Gane capliates the only previausly reported 10w dose investigations $[9,10]$. Irradiations performed in Bitu in the HVE at both $30 \mathrm{~N}$ and rocin temperature have allowed us to perform this investigation without the complications seen by the previous investigators. It is the results of these studies that are reparted in this paper.

\section{EXPERTMPNIAL}

The experfwents were performed in the High-Voltage Electron Microsogpe Ion Acoelerator Facility at Argane National Iaboratory. This facility cansists of two acelerators, a $300 \mathrm{keV}$ Texas huclear acoelerator and a NEC 2 KeV Tandem acoelerator, either of wich prowuce ian beams that can be directed onto the HVBM sample position by an lan-heam interface. For these experiments ally the first accelerator was used. The details of this facility can be foum in referenoe [11]. The low-temperature experiments have been performed using a double-tilt, liguid-helium cooled, HVI sample stage which is capable of supporting samples during in situ irradiations and HVEM examination at cantrolled temperatures between 10 and $300 \mathrm{~K}$. It should be enphasized that it is the powerful capabilities of this facility, cryogenic temperatures and in situ infadiations, that have allowed this investigation to be made.

The samples included both $n$-type ( $1 \times 10^{18} \mathrm{si}$ atams $\left.\mathrm{cm}^{-3}\right)$ and undoped semi-insulating (100) wafers of GaAs. Studies were made in both materials in an attempt to acoount for the discrepancy between our results and those of previous investigations $[9,10]$. The TOM samples were prepared using a chemical thiming technique in a static bath solution of 4 pants $\mathrm{H}_{2} \mathrm{SO}_{4}$, 1 part $\mathrm{H}_{2} \mathrm{O}_{2}$, and 1 part $\mathrm{H}_{2} \mathrm{O}$ at $35^{\circ} \mathrm{C}$.

The samples were irradiated in a non-channeling direction with $\mathrm{Ar}^{+}$and $\mathrm{Kr}^{+}$ions with incident energies of $50 \mathrm{keV}$. Ion doses rarged from $2 \times 10^{11}$ to $5 \times 10^{13}$ ians $\mathrm{cm}^{-2}$. Dose rates were typically less than $3 \times 10^{10}$ ions $\mathrm{cm}^{-2}$ $\sec ^{-1}$. The electron microsocpy was performed with the HVEM cperating at 200 KV. For the most part, micrographs were taken in dark field under dynamical two beam conditions using the fundamental reflection $g=(220)$. It was under these diffracting conditions that the most distinct defect images were cbserved. The contrast we observe is similar to that seen in silicon by other researchers [12].

To investigate the degree and extent of disordering produced by the cascades pairs of micrographs have been taken using the (200) superlattice and $(400)$ fumdamental reflections. The defect contrast using fundamental reflections cocurs because of a significart difference in the structure of amorphous and crystalline material. On the other hand, regions high in antisite defects yet etill crystalline can be imaged with the (200) superlattice reflection because it is present as a result of the ordering of the $\mathrm{Ga}$ and $\mathrm{As}$ an distinct sublattices. This effect is comparable to the use of superlattice reflections to directly abserve the disordered zones created by cascades in ordered alloys such as $a_{3} A^{4 l}$ [13].

\section{RESUITS AND DISCUSSION}

The results fram specific irradiations are summarized in Table 1 and are discussed in detail below. In the table and subsequent text the defect yield is defined as the number of visible amorphous zanes produced per incident ion. 
Trble I

Datect yialo

\begin{tabular}{|c|c|c|c|}
\hline MATERIAL & 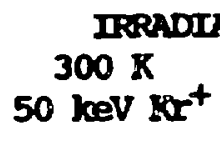 & $\begin{array}{l}30 \mathrm{~K} \\
50 \mathrm{keV} \mathrm{Ret} \\
\end{array}$ & $\begin{array}{l}\text { ND ION } \\
30 \mathrm{~K} \\
50 \mathrm{keV} \mathrm{Ar}^{+}\end{array}$ \\
\hline N-TYPE & 0.18 & $0.78^{\star}$ & 0.17 \\
\hline SEMI-INSULATING & 0.19 & 0.95 & - \\
\hline
\end{tabular}

\section{$30 \mathrm{~K}$ Imadiations with $50 \mathrm{keV} \mathrm{Kr}^{+}$and $\mathrm{Ar}^{+}$ions}

The micrographs presented in figure 1 show that in the sent-insulating material a high density of amphous wones are prochoed ouring ion bombarcment at: low temperatames; a similar result was abtained for the $n$ type material. At these ion doses (< $\left.10^{12} \mathrm{ians} / \mathrm{cm}^{2}\right)$, the degree of spatial cverlap of the cascades is negligible and the amorphous zones are formed iran isolated indivicual displacement cascades. The zones ane evicient immediately following the irradiation and on not develop with time. Comparison of the micrographs reveals that the density of the rmorphous zones is higher following the $\mathrm{Kr}^{+}$Ian than the $\mathrm{Ar}^{+}$Ian ircodiation; the Yileld difference is between a factor of 3 to 4 times greater for the $\mathrm{Kr}^{+}$ion irradiation, see Table 1. The area cocpled by the anompous zones is also
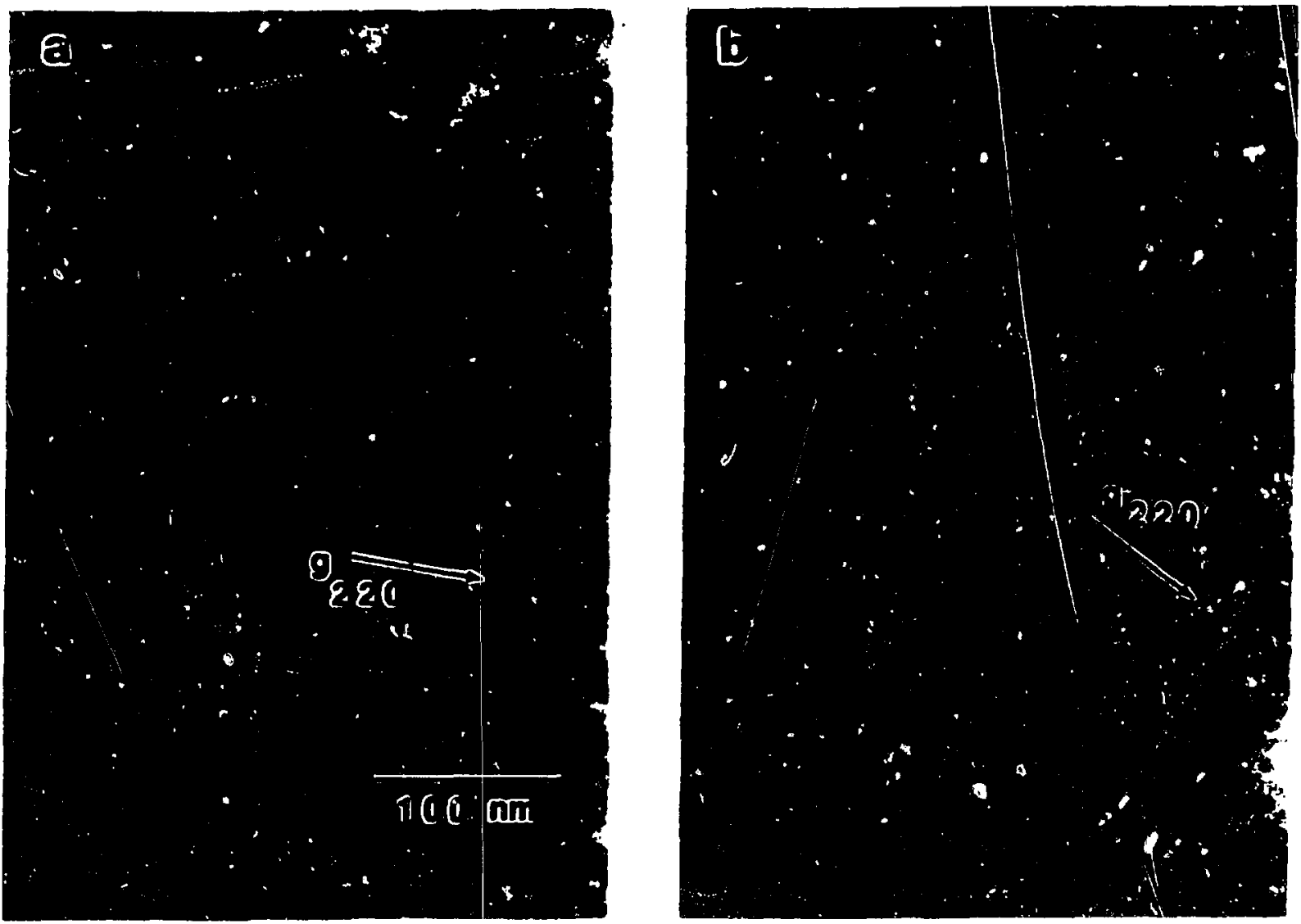

Fig 1. Comparison of the amorohous zanes produced at $30 \mathrm{~K} \mathrm{bV} \mathrm{(a)} \mathrm{Kr+} \mathrm{and}$ 
dependent on the mass of the inocming Ian, being on averroge langare for the

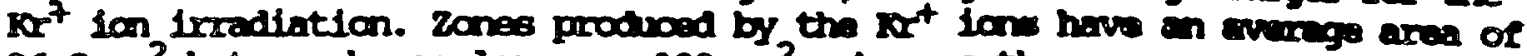
$36.8 \mathrm{~mm}^{2}$ but can be as large as $100 \mathrm{~nm}^{2}$, wereas the averago arca for zones produced by $\mathrm{kr}^{+}$ion irradiaticns is $30.4 \mathrm{nt}^{2}$ and the largest $75 \mathrm{~nm}^{2}$. The yield and size differences are readily understood in tenns of the cascade parameters for the different ions.

\section{Gystallization of the monphous zones during wamup $30 \mathrm{~K}$ to $300 \mathrm{~K}$}

Amealing of the materials from 30 to $300 \mathrm{~K}$ caused the individual zanes to crystallize. The yield after warm-up drops by 8 factor of about 4 and is now equal to the yield at rocm temperature immodiately after irradiation. The micrographs in Figure 2 show the results of a step anneal from 30 to $300 \mathrm{~K}$, the zones remain as the temperature is increased to $250 \mathrm{~K}$. Above $250 \mathrm{~K}$ the zones start to recrystallize, with the yield decreasing by a factor of 0.44 between 250 and $285 \mathrm{~K}$. Area size distributions show no change with increasing temperature, indicating that the size of the zone does not dictate the order in which the zones crystallize. The loss of mozphous zones at temperatures $>250 \mathrm{~K}$ corresponds with one of the recovery peaks in the electrical properties as determined by resistivity measurements [14] . The defect responsible for the reoovery has not been unambiguously identified.
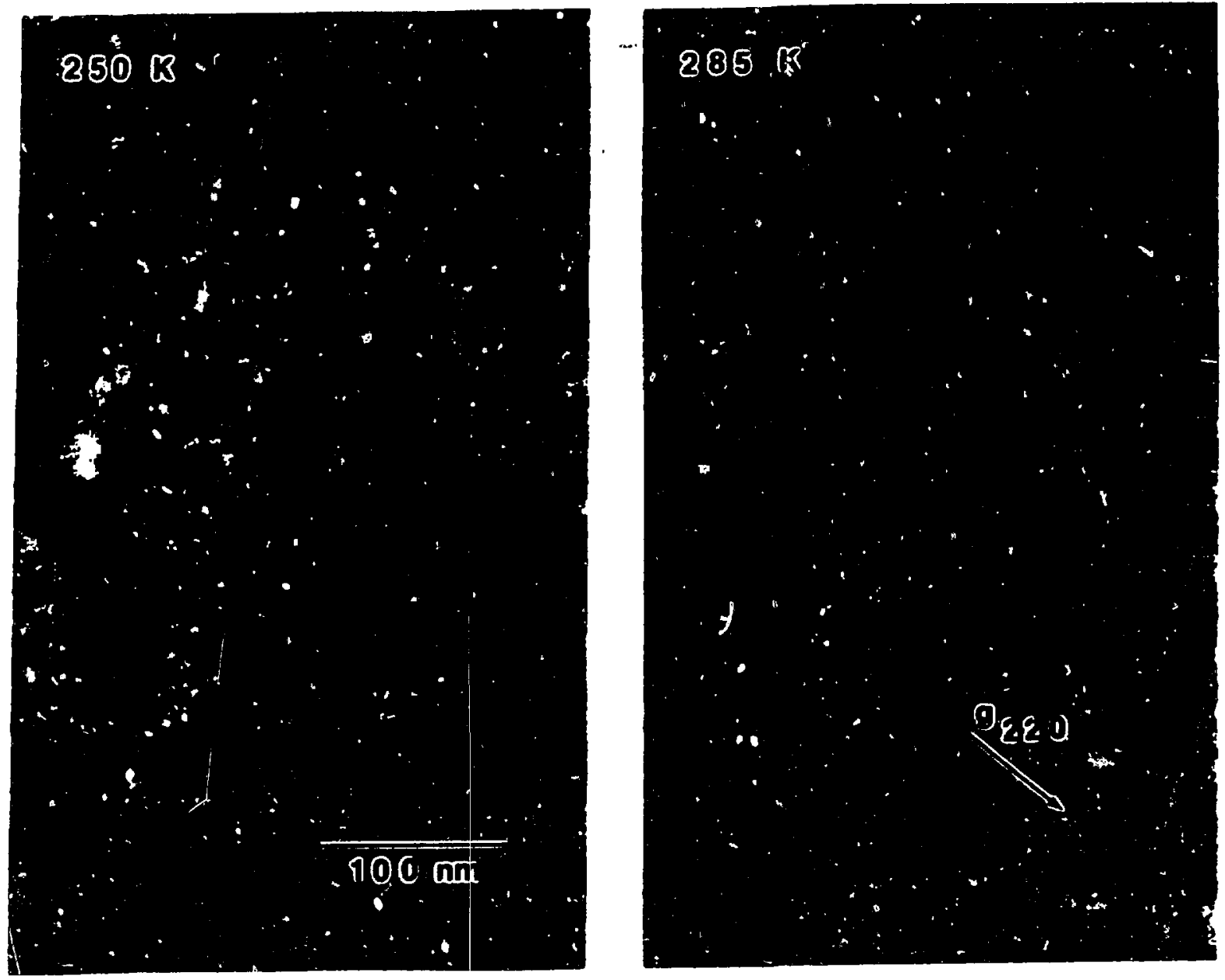

Figure 2. Lensity of defects as a function of annealing temperature from 30 
For both n-type and semi-insulating Gass, the yleld abtaingd fram roam temperature irradiations is lower than the yield obtained from low temperature irradiations, see Table 1. These sones are ogain formed from isolated displacement cascades. The rocm temperature yield decreases with time at roan temperature. It is this rocm temperature crystalization effect which explains why previous work found no zones at these ian doses. The crystallization rate also increased under the eiectron beam; this is probably a consequence of beam heating rather than collisional assistance. An excomple of the roam temperature armealing in semi-insulating GaAs is shown in Fig 3. The micrographs in Fig 3(a and b) compare the same region of sarple 30 and 60 minutes after irradiation. The zanes indicated by the arrows are not present in the second micrograph. After 20 hours, the yield has decreased fram 0.19 to 0.09 . Further time at roan temperature removes all isolated amorphous zones. Analysis of the zone area distributions showed that there was no preferential recovery of either large or small isolated zones. The low yield at roam temperature and the results of earlier work can now be understood in terms of the competition between creation and crystallizacion of the amorphous zones. At high for doses (>1013 ians $\mathrm{cm}^{-2}$ ) and at higher dose rates where the displacement cascades overlap both spatially and temporally (i.e. within the lifetime of the amorphous zone) stable amorphous zones can form. The greater stability of amorphous zones formed under these irradiation conditions is not understood but may reflect

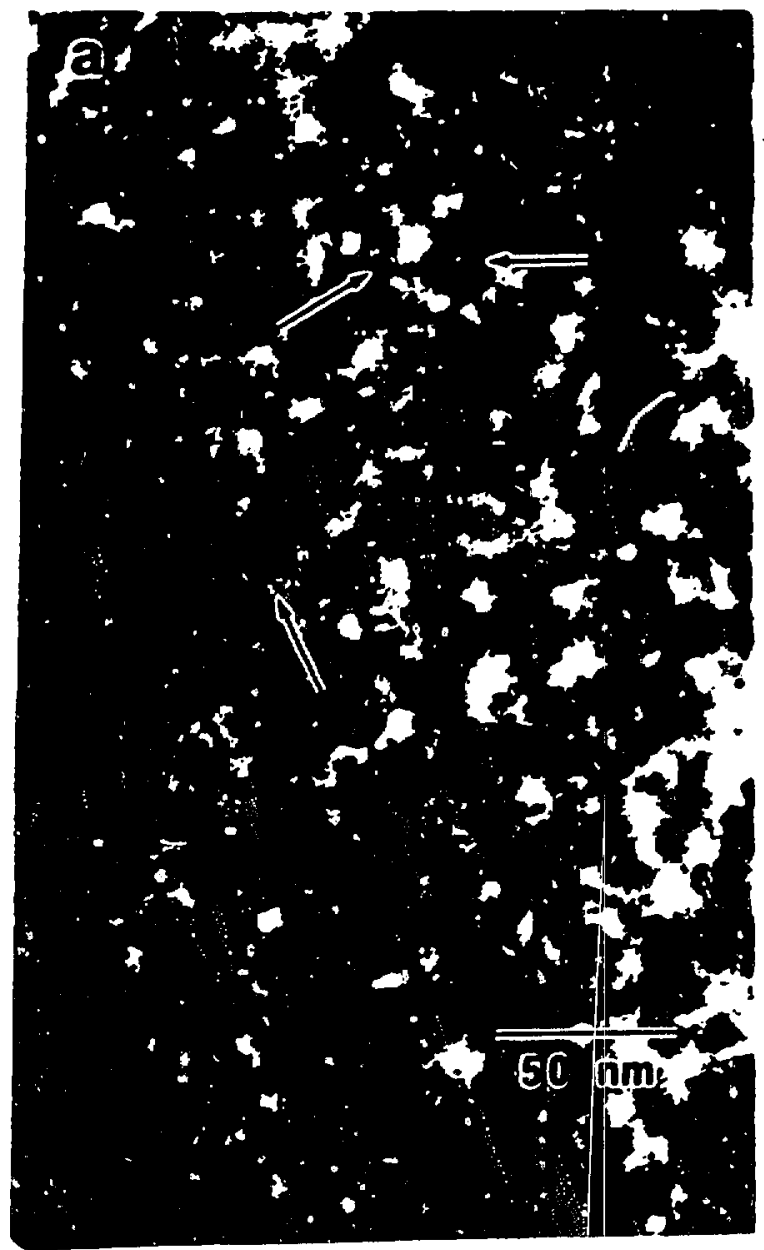

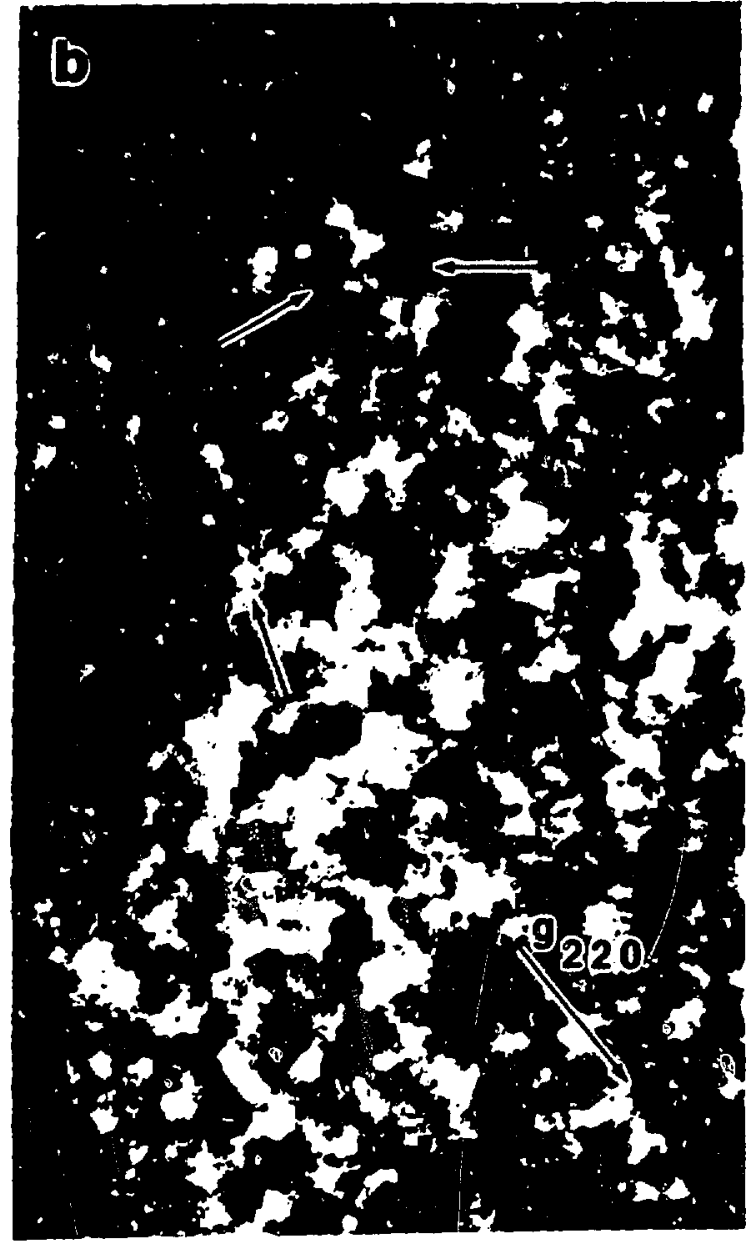

Figure 3. Roam temperature annealing at (a) 30 and (b) 60 minutes after the irradiation. The arrows in (a) and (b) mark defects that have disappeared. The sample was irradiated to a dose of $9 \times 10^{11}$ ions $\mathrm{cm}^{-2}$ with $50 \mathrm{keV} \mathrm{kr}^{+}$ions. 


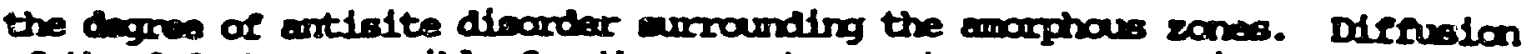
of the cafect reeponsible for the rocm temperature reoovery is expected to be dependant on the degree of antistice dfsonder, being slower the greater this discucler. Heasuremerits of the extent of the antisite disorder zone assoctated with the amomphous zone are cauplicated, hovever, a preliminary cauparisons of iroges taken using the (200) opperlattioe and $(400)$ fundamental

reflections indicate that the antisite disordered zones, at least in the low temperature irradiations, are larger than the amophous zones. The degree of antisite disorder associated with omorphous zones and its deperdence on ion dose and dose rate is the subject of further investigation.

\section{SUMPRY}

Amorphous zones have been abserved to form in both semi-insulating and $n$-type GaAs from single isolated displacement cascades. The yield from room temperature irradiations is less than that from low temperature irradiations cue to the continual room temperature crystallization of the amorphous zones. The zane crystallization rate is not related to size of the amorphous region but may be related to the size and degree of the antisite disorder zone that is assciated with the amorphous zone.

\section{ACKNOWLEDGEMENS}

This work was performed under Department of Energy, Bes-Materials Science contracts W-31-109-Eng-38 (ANL) and ACO9-76ERO1198(U of I). The use of the electron microscone facilities in the MRL at the University of Illinois and the HVEM facility at ANL are gratefully appreciated. The authors would like to acknowledge Ir.M.L.Jenkins (Oxford University) for his invaluable caments on this subject.

\section{REFERENCES}

1. S.J.Peartan, J.M.Poate, F.Sette, J.M.Gibson, D.C.Jacabson and J.S.Williams, Nucl.Instr. Meth. ,B19/20, 369 (1987) .

2. D.K.Sadana, Nucl.Instr. Meth. , B7 $\triangle 8,375$ (1985).

3. H.J.Stein, F.L.Vook, D.K.Brice,J.A.Borders and S.T.Picraux, in Ion Implantation, edited by F.H.Eisen and L.T. Chadderton (Gordon and Breach Science Publishers, Iondon, 1971),p.17.

4. F.F.Morehead,Jr. and B.L.Crowder, Rad.Effects, 6,27 (1970).

5. R.P.Webb and G.Carter, Rad.Effects 59,69 (1981).

6. W.H.Weisenberger, S.T.Picraux and F.L.Vook, Rad. Effects, ․,121 (1971).

7. D.V.Stevanovic, N.P.Tognetti,G.Carter, C.E.Christodonlides, A.M. Thrahim and D.A.Thompson, Rad. Effects, 71,95 (1983).

8. N.P.Tognetti, G.Carter, D.V.Stevanovic and D.A.Thampson, Rad.Effects, $\underline{66}$ 15 (1982)

9. T.J.Chandler and M.L.Jenkins in Microsoopy of Semioonchuctor Materials, 1983, Inst. Phys.Conf.Ser., 67, London p. 297.

10.M.L.Jenkins, T.J.Chandler, I.M.Robertson and M.A.Kirk, in Microsogoy of Semiconductor Materials, 1985, Inst. Phys. Oonf.Ser., 76, London p.227.

11.A.Taylor, J.R.Wallace, E.A.Ryan, A. Phil ippides and J.R.Wrabel, Mucl. Instr. Meth. , 189,211 (1981).

12.L.M.Howe and M.H.Raimville, Nucl.Instr.Meth.,182/183, 143 (1981) .

13.T.J.Black, M.L.Jenkins, C.A.English and M.A.Kirk. Proc. Royal Soc., A409, 177, (1987).

14. K. Thammen, Rad.Effects, 2,201 (1970) . 